Volume 2 Nomor 22018

\title{
MEDIA PUBLIKASI HUMAS DALAM PENDIDIKAN
}

\author{
Hannah Mahfuzhah, Anshari \\ Universitas Nurul Jadid \\ PP Nurul Jadid Karanganyar Paiton Probolinggo \\ hannachatib16@gmail.com
}

Abstrak: The effort to build good relations with the media is one way to make the institution's image better. Media use activities are carried out to influence the public to achieve organizational goals. Mass media is usually used by organizations or educational institutions to build the image of the institution.

In order to be able to perform its functions properly, the role of public relations must be carried out by competent people in their fields. A publicist must be smart in choosing publications, so that the intent to be conveyed to the public can be appropriate and on target. Although the public relations and mass media have a mutually beneficial relationship, there are some things that need to be considered so that especially for educational institutions that have the aim of publishing educational institutions so that a good relationship between public relations and mass media is maintained.

Keywords : publication media, public relation, education

\section{PENDAHULUAN}

Persaingan dalam dunia pendidikan menjadi tidak terelakkan lagi, hal ini menuntut pengelola pendidikan untuk menyingsingkan lengan baju serta lebih intens dalam mempromosikan lembaga pendidikannya. Menurut Hasan Baharun perkembangan teknologi informasi yang sedemikian cepat tidak saja mengubah cara orang berkomunikasi dan bekerja, jauh daripada itu telah membuat alam persaingan baru.(Baharun, 2016)

Dalam mempromosikan lembaga pendidikan, menuntut keaktifan dan peran serta warga madrasah maupun peran masyarakat secara luas sebagai konsumen pendidikan. Tanpa adanya peran serta masyarakat, lembaga pendidikan akan berjalan sepihak dan sulit untuk berkembang.(Indrioko, 2015) Oleh karena itu, perlu diadakannya komunikasi antara lembaga pendidikan dan masyarakat, dan disinilah peran humas sangat diperlukan.

Manajemen humas dalam pendidikan merupakan mediator yang menghubungkan antara organisasi dengan masyarakat (public) demi tercapaianya tujuan organisasi dan harapan masyarakat dengan produk yang dihasilkan. Berdasarkan satuan tugas tersebut seorang humas dituntut untuk mampu menjem batani keterlibatan seluruh anggota masyarakat sekolah, guru, karyawan, siswa, orang tua, lingkungan, perguruan tinggi dan lembaga pemerintah dan swasta 
$\gamma$-tanzim $\begin{aligned} & \text { Hannah Mahfuzhah \& Anshari } \\ & \text { Media Publikasi Humas Dalam Pendidikan }\end{aligned}$

\section{Volume 2 Nomor 22018}

untuk ikut peduli dalam mengoptimalkan kemampuan dan kerja sama sesuai dengan kemampuannya masing-masing, dan membantu kepala sekolah dalam kegiatan pengelolaan sekolah.(Rahmat, 2016)

Setidaknya seorang Humas dituntut untuk memiliki 4 kompetensi agar dapat menjadi humas yang baik, yaitu:

1. Communicator

Sebagai juru bicara organisasi, PR berkomunikasi secara intensif melalui media dan kelompok masyarakat.

2. Relationship

Merupakan kemampuan PR membangun hubungan positif antara lembaga yang diwakilinya dan publik internal maupun eksternal.

3. Backup Management

Melaksanakan dukungan manajemen atau menunjang kegiatan departemen lain dalam perusahaan seperti bagian pemasaran, operasional, teknik, keuangan, dan personalia demi terciptanya tujuan bersama dalam suatu kerangka tujuan pokok perusahaan atau organisasi.

4. Good image maker

Menciptakan citra perusahaan dan publisitas positif merupakan prestasi, reputasi dan sekaligus menjadi tujuan utama bagi aktivitas public relations dalam melaksanakan manajemen kehumasan membangun citra organisasi atau perusahaan. (Kholisoh, 2015)

Humas bekerja, mendukung pembinaan dan pembangun upaya yang saling menguntungkan melalui komunikasi, pengertian, penerimaan, dan kerja sama yang baik antara organisasi dengan publiknya.(Rahutomo, 2013) Humas dituntut untuk memiliki manajemen komunikasi yang efektif dalam rangka memenuhi peran dan fungsinya sendiri dalam mendukung kegiatan perusahaan. (Musyarrofah, 2018)

Pada umumnya, seorang humas memiliki setidaknya 5 agenda besar dalam aktivitas manajerialnya, yaitu:

1. Hubungan dengan pers

Merupakan relasi yang dibangun dan dikembangkan dengan media untuk menjangkau publik guna meningkatkan pencitraan, kepercayaan, dan tercapainya 
$\gamma$-tanzim $\begin{aligned} & \text { Hannah Mahfuzhah \& Anshari } \\ & \text { Media Publikasi Humas Dalam Pendidikan }\end{aligned}$

\section{Volume 2 Nomor 22018}

tujuan-tujuan individu maupun organisasi/perusahaan. Tujuan umum dari media relations antara lain:

a. Meningkatkan kesadaran terhadap organisasi/perusahaan (corporate) dan produk

b. Mengubah sikap publik/masyarakat

c. Mendorong tindakan yang mendukung kepentingan organisasi.

2. Publisitas

3. Komunikasi perusahaan, kegiatan yang meliputi komunikasi internal dan eksternal untuk meningkatkan saling pengertian

4. Lobbying

5. Counselling (Anom, 2004)

Setiap lembaga pendidikan memiliki karakteristiknya masing - masing, visi dan misi, serta budaya serta kultur sekolah yang diunggulkan. Hal - hal tersebut menjadi lahan kerja bagi Waka Humas untuk dipublikasikan kepada masyarakat luas, agar kebutuhan masyarakat akan informasi tersebut dapat terpenuhi.

Media massa mempunyai arti penting bagi organisasi terutama sebagai saluran untuk menyampaikan publikasi pada masyarakat luas secara umum dan publik (stakeholder) secara umum. Selain kemampuan dalam membangun wacana maupun membentuk opini, media juga banyak digunakan untuk membangun citra lembaga.(Raharjo, 2016)

Berangkat dari hal tersebut, lembaga yang sudah baik dan berkualitas, harus diimbagi dengan penempatan Waka Humas yang tepat yang mumpuni dibidangnya. Dengan harapan Waka Humas tersebut dapat menciptakan image yang baik kepada masyarakat dan stakeholder, dengan melakukan hubungan yang harmonis dengan media massa melalui publisitas lembaga dengan memilih media publikasi yang tepat.

\section{KETERBUKAAN INFORMASI PUBLIK DALAM AKTIVITAS MANAJERIAL}

Public Relations merupakan fungsi manajemen untuk mencapai target tertentu yang memiliki program kerja yang jelas dan rinci, mencari fakta, merencanakan, mengkomunikasikan hingga mengevaluasi hasil-hasil apa yang telah dicapai.(Artis, 2011) Dengan adanya Public Relations diharapkan organisasi dapat berjalan dan berkembang dengan baik. Hal ini karena eksistensi Public relation dalam suatu lembaga atau instansi 
$\gamma$-tanzim $\begin{aligned} & \text { Hannah Mahfuzhah \& Anshari } \\ & \text { Media Publikasi Humas Dalam Pendidikan }\end{aligned}$

\section{Volume 2 Nomor 22018}

merupakan jembatan (mediasi) penyambung antara lembaga dan publiknya. Perkembangan Public relation bertujuan untuk agar tiap-tiap organisasi dalam publik mendesain hubungannya dengan berbagai elemen masyarakat, agar tercapai hubungan yang serasi dan harmonis.(Afkarina, 2018)

Aktivitas humas merupakan aktivitas komunikasi dua arah antara organisasi dengan publik, yang memiliki tujuan untuk saling menumbuhkan pengertian, percaya dan saling membantu atau kerjasama. Pengertian humas tidak hanya sekedar komunikasi yang mempunyai tujuan. Namun dalam mencapai tujuan itu, humas harus memiliki strategi-strategi atau formula-formula yang dapat dilakukan oleh humas untuk mencapai tujuan yang ingin dicapai tersebut.(Toding, 2017)

Strategi public relation dapat dibangun dengan menumbuhkan kepercayaan dari publik agar mendapat citra positif. Tahapan strategi dapat dilakukan dengan cara sebagai berikut:

1. Penelitian (Research)

Sebelum melakukan komunikasi pada masyarakat, petugas public relation harus mengetahui lebih dahulu mengetahui siapa yang akan diberi pesan dan bagaimana keadaan komunikan. Untuk itu, perlu dilakukannya penelitian. Tanpa mengetahui keadaan publik, maka komunikasi yang dilakukan oleh petugas public relation tidak mengenai sasaran. Penelitian bisa menggunakan cara survey, studi kasus, dll.

2. Perencanaan (Planning)

Setelah mendapatkan fakta-fakta/ data-data dari hasil penelitian, tahap berikutnya yaitu membuat perancangan yang tepat, sehingga mencapai sasaran yaitu merebut public opinion .

3. Kegiatan (Action)

Setelah rencana cukup matang dan disetujui oleh pihak yang berwenang, maka rencana tersebut dilaksanakan.

4. Evaluasi (Evaluation)

Tahap ini dimaksudkan untuk mencocokan sampai dimana program atau rencana yang telah dilaksanakan.(Herlina, 2015)

Agar strategi tersebut dapat tercapai, maka perlunya menaati aturan yang telah ditetapkan. Disbutkan dalam Undang Undang Republik Indonesia no 14 tahun 2008 tentang keterbukaan informasi public, bahwa yang disebut informasi publik adalah informasi yang 
$\gamma$-tanzim $\begin{aligned} & \text { Hannah Mahfuzhah \& Anshari } \\ & \text { Media Publikasi Humas Dalam Pendidikan }\end{aligned}$

\section{Volume 2 Nomor 22018}

dihasilkan, disimpan, dikelola, dikirim, dan atau diterima oleh suatu Badan Publik yang berkaitan dengan penyelenggara dan penyelenggaraan negara dan atau penyelenggara dan penyelenggaraan Badan Publik lainnya yang sesuai dengan Undang-Undang ini serta informasi lain yang berkaitan dengan kepentingan publik. Dalam hal ini, informasi publik bersifat transparan dan memungkinkan untuk dapat diakses oleh setiap pengguna informasi publik, dengan tepat waktu, cepat, mudah, biaya ringan, dan cara sederhana.(DPRRI, 2008)

Selain itu, menurut Arthur W. Page sebagaimana dikutip oleh Mubarok (Marhaeni, 2016), menyebutkan sejumlah prinsip yang dapat diaplikasikan dalam praktek public relation dalam menjaga hubungan lembaga dengan publiknya:

1. Tell the Truth (Memberitakan Kebenaran)

Biarkan publik tahu apa yang terjadi dan sediakan gambar yang akurat dari karakter ideal dan praktek lembaga. Berikan visual yang nyata, dan sediakan informasi yang benar - benar dibutuhkan oleh publik. Dengan demikian, publik dapat mengetahui apa yang sebenarnya terjadi tanpa ada yang ditutupi. Kebutuhan informasi yang dibutuhkan mereka dapat terpenuhi, dan hubungan antara lembaga dengan publiknya dapat dijaga dengan baik.

2. Prove it with Action (Buktikan dengan Tindakan)

Setiap perilaku, kinerja maupun kegiatan lembaga, selalu menjadi sorotan publik. Perilaku lembaga, merupakan sumber informasi bagi publik dalam menilai kinerja lembaga. Perilaku tersebut dinilai dari arus informasi, cara kerja anggota lembaga, dan segala kejadian maupun peristiwa yang terjadi dalam lembaga.

3. $\quad$ Listen to The Customer (Dengarkan Suara Konsumen/Masyarakat)

Demi eksistensi lembaga, mengertilah pada kebutuhan dan keinginan publik.

4. Manage for Tomorrow (Siapkan Diri untuk Esok)

Antisipasi dengan reaksi yang diberikan oleh publik dan hilangkan hal - hal yang dapat memberikan kesulitan. Penting bagi sebuah lembaga untuk menyusun setiap kegiatan, dan merencanakan program maupun aktifitas sehari-hari dengan baik. Merencanakan kegiatan jangka panjang dapat bermanfaat dalam menghindarkan problem maupun kekacauan yang bisa saja terjadi di masa mendatang.

5. Conduct Public Relationss as If The Whole Company Depends On it (Lakukan Tindakan PR Seakan Seluruh Lembaga Bergantung Padanya) 
$\gamma$-tanzim $\begin{aligned} & \text { Hannah Mahfuzhah \& Anshari } \\ & \text { Media Publikasi Humas Dalam Pendidikan }\end{aligned}$

\section{Volume 2 Nomor 22018}

PR lembaga merupakan fungsi dari manajemen. Strategi lembaga tidak dapat dilaksanakan tanpa memikirkan dampaknya secara luas terhadap publik. Profesional PR yaitu merancang kebijakan yang dapat menangani berbagai aktifitas komunikasi lembaga dengan cakupan yang luas. Salah satu bentuk perjuangan adalah dengan bekerja, bekerja keras juga cerdas.

\section{Remain Calm, Patient and Good Humored}

Bersikaplah secara konsisten, tenang dan perhatian saat menyampaikan informasi, atau melakukan kontak dengan publik. Bila terjadi krisis, tetaplah tenang dan ingat bahwa mengkomunikasikan masalah dengan kepala dingin adalah jalan yang terbaik.

\section{JENIS - JENIS PUBLIKASI DALAM KEHUMASAN}

Organisasi, baik itu kecil, sedang, atau besar pada dasarnya akan selalu membutuhkan sentuhan komunikasi aktif guna menumbuhkan partisipasi publik dalam pengembangan operasional perusahaan.(Ishak, 2012) Dan publikasi merupakan cara yang sering digunakan oleh humas untuk mempromosikan lembaganya. Biasanya dilakukan dengan dua cara, yaitu:

1. Publikasi lembaga dengan cara kegiatan tidak langsung

Kegiatan tidak langsung merupakan kegiatan yang berkomunikasi dengan masyarakat melalui media perantara tertentu, misalnya dengan melalui radio, media cetak, televisi, pameran dan internet.

2. Publikasi lembaga dengan cara kegiatan langsung

Kegiatan langsung adalah kegiatan yang dilaksanakan secara langsung tanpa perantara media dan dilakukan dengan cara tatap muka, seperti rapat bersama, konsultasi dengan tokoh masyarakat, bazar sekolah dan ceramah.(Indrioko, 2015)

\section{PEMILIHAN MEDIA PUBLIKASI}

Bertambahnya tingkat kecerdasan publik dalam memberikan dan menyebarkan informasi, memerlukan kontrol bagi berbagai penyampaian dan penyebaran informasi terkait dengan aktivitas informasi lembaga. Peran public relation diharapkan dapat menyeimbangkan berbagai informasi agar tidak sampai merugikan kepentingan dan rencana lembaga. Hal ini terkait dengan nama baik dan eksistensi lembaga, untuk mewujudkan cita - cita ini maka lembaga memerlukan peran serta public relation yang proaktif dan kreatif.(Adhrianti, 2016) 


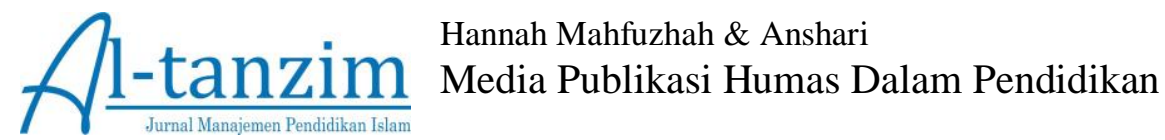

\section{Volume 2 Nomor 22018}

Dalam kegiatan publikasi lembaga/sekolah, seorang public relation terlebih dahulu harus mengenal pasar yang akan dijadikan target publikasi, agar promosi yang ditawarkan menjadi tepat sasaran. Misalnya untuk masyarakat ekonomi menengah ke bawah, publikasi lembaga dapat dilakukan dengan media cetak seperti brosur, dll. Berikut macam - macam media publikasi yang dapat digunakan:

1. Media Cetak

Media cetak merupakan sebuah media yang mempunyai fungsi sebagai media penyapaian informasi. Media cetak merupakan media informasi yang terdiri dari lembaran dengan sejumlah kata, foto, maupun gambar dengan berbagai macam warna, yang memiliki fungsi pokok untuk menyampaikan informasi atau menghibur. Media cetak dapat dikatakan pula sebagai suatu dokumen yang mempublikasikan apa yang dikatakan oleh orang lain baik berupa kata - kata ataupun rekaman peristiwa dan foto yang ditangkap oleh jurnalis dan dan kemudian diedit sehingga layak untuk disampaikan kepada masyarakat .(Abbas \& Pasallo, 2013)

Kelebihan media ini adalah dapat menjangkau semua lapisan masyarakat, dan tergolong murah. Namun, media ini hanya terjadi komunikasi satu arah sehingga penyampaian berita sangat tergantung pada konsep penulis.

2. Media Eletronik

Media eletronik terdiri dari televisi dan radio. Kelebihan kedua media ini adalah dapat menjangkau masyarakat yang lebih luas dari pada media cetak.

Berhasil tidaknya penyebaran infornasi melalui televisi sebagai media publisitas madrasah tergantung pada program yang disiapkan, dalam program tersebut telah disusun pokok - pokok permasalahan yang akan disajikan kepada penonton/pemirsa. Penyampaian informasi melalui media telivisi sangat efektif dan mampu menjangkau daerah pelosok, pedesaan maupun pegunungan, penggunaan dengan media telivisi ini dapat dilakukan dengan berbagai acara antara lain : (a) ceramah umum, (b) wawancara, (c) sandiwara, (d) diskusi, (e) humor, (f) cerdas tangkas, (g) kegiatan pentas seni, dll.

Sedangkan radio memiliki beberapa keunggulan yaitu: (a) teks yang akan di siarkan dapat disiapkan sebelum waktu penyiaran, (b) tidak dipengaruhi faktor komunikator, seperti sikap dan tinhkah laku, (c) Dapat melewati batas ruang, waktu serta jangkauan luas, dan (d) dapat dibantu latar belalakang musik.(Wahyuni, 2018)

3. Media Sosial 
$\gamma$-tanzim $\begin{aligned} & \text { Hannah Mahfuzhah \& Anshari } \\ & \text { Media Publikasi Humas Dalam Pendidikan }\end{aligned}$

\section{Volume 2 Nomor 22018}

Media sosial atau dewasa ini sering disebut dengan social media adalah "websites and applications that enable users to create and share content or to participate in social networking"'(Griessner, 2012).Media sosial hadir dan merubah paradigma berkomunikasi di masyarakat saat ini. Komunikasi tak terbatas ruaang, jarak, dan waktu. Bisa dilakukan dimana saja dan kapan saja, tanpa harus bertatap muka. Dengan hadirnya aplikasi jejaring sosial seperti Facebook, Twitter, Instagram dan semacamnya, orang - orang dapat saling berinteraksi tanpa harus bertemu langsung. Jarak bukan menjadi masalah lagi dalam berkomunikasi.(Dwi \& Watie, 2011)

\section{MEMBINA HUBUNGAN DENGAN LEMBAGA PERS}

Definisi Pers menurut Undang- Undang No. 40 Tahun 1999 Pasal 1 butir (1) adalah sebagai suatu lembaga sosial dan wahana komunikasi massa yang melaksanakan kegiatan jurnalistik, meliputi mencari, memperoleh, memiliki, menyimpan, mengolah dan menyampaikan informasi baik dalam bentuk tulisan, suara, gambar, suara dan gambar, serta data dan grafik maupun media elektronik, dan segala saluran yang tersedia.(Surbakti, 2015)

Dalam menjalankan program kerja dan berbagai aktivitasnya, humas dan wartawan tidak mungkin dapat dipisahkan, karena keduanya saling membutuhkan, yaitu humas menjadi sumber informasi bagi wartawan (pers), sedangkan wartawan (pers) menjadi wadah publisitas untuk humas, agar setiap program kerja organisasi lebih dikenal dan memiliki nilai guna bagi masyarakat luas.(Aras, 2014)

Salah satu fungsi humas adalah membangun hubungan secara baik antara organisasi dengan publik, baik secara internal maupun ekternal. Humas internal berperan menjadi penghubung antara management dengan para pekerjanya, agar tidak terjadi misscommunication yang dapat mengganggu kenyamanan bekerja dan loyalitas karyawan. Sedangkan peran humas ekternal adalah untuk menyusun berbagai program demi hubungan baik antara perusahaan dan publik luar, seperti melakukan kegiatan publisitas.(Diana, 2010)

Humas dan media merupakan mitra kerja yang saling menguntungkan, penting dan tidak terpisahkan. Media massa adalah sebuah sarana untuk berkomunikasi atau menyampaikan suatu berita pada masyarakat dalam kurun waktu yang singkat.(Ardhoyo, 2013) 


\section{Volume 2 Nomor 22018}

Meski demikian untuk membina hubungan yang baik dengan media massa terlebih dahulu harus dipahami perbedaan tugas dan fungsi diantara humas dan pers agar tidak terjadi pertentangan dalam menjalankan tugas dan fungsinya masing-masing.

Secara garis besar fungsi pers memberikan informasi, penyebaran pengetahuan baru, baik yang memiliki unsur mendidik ataupun menghibur. Secara khusus fungsi pers adalah mempengaruhi opini masyarakat, dan melakukan sistem kepengawasan sosial. Fungsi pers tersebut sangat bertentangan dengan fungsi humas yang justru melakukan aktifitas publikasi yang hanya bersifat positif saja, seperti mendidik, memberikan informasi atau pesan untuk pengenalan, mempengaruhi opini masyarakat dengan hal - hal yang positif dan menjauhkan unsur - unsur pemberitaan atau publikasi yang bersifat negatif di tengah masayarakat.

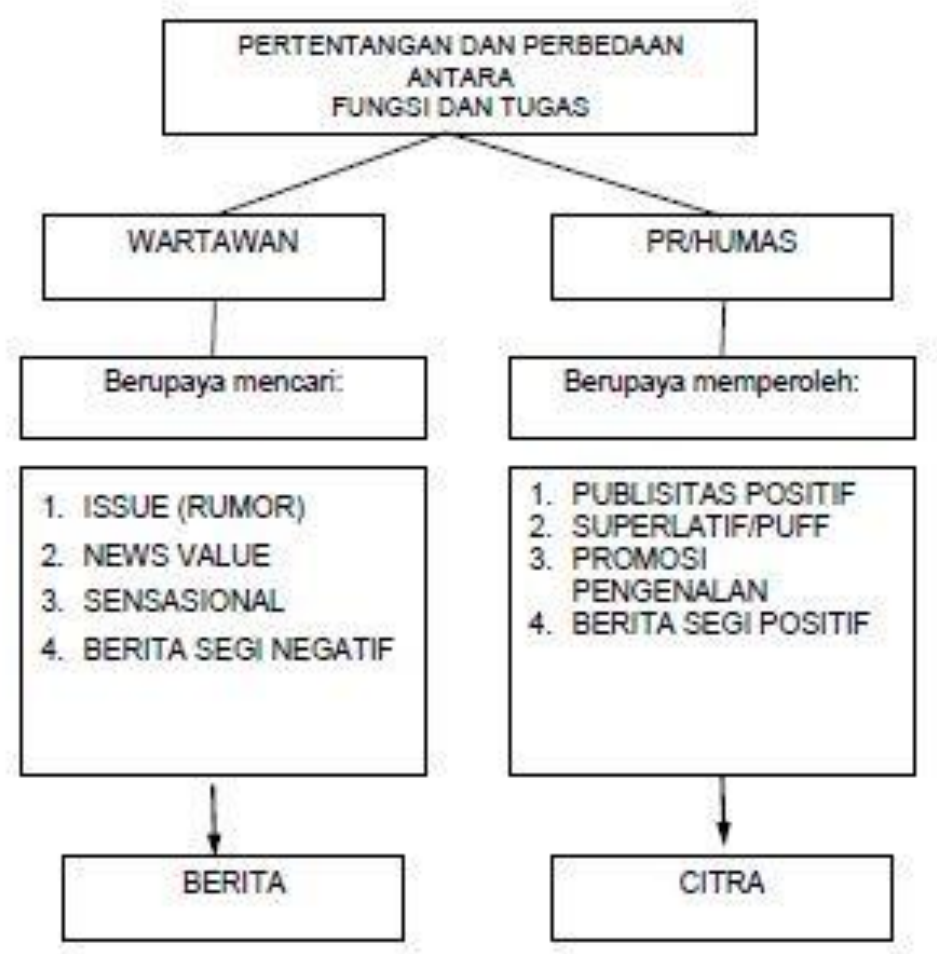

Perbedaan fungsi tersebut harus dekelola dengan baik agar tercipta hubungan yang harmonis dan saling menguntungkan antara kedua belah pihak. Dengan adanya kerjasma yang baik antara humas dan pers diharapkan dapat menumbuhkan opini public yang baik juga, yang dapat menguntungkan citra lembaga/organisasi dimata publiknya.

Hubungan yang baik dengan media massa dapat dicapai apabila humas menerapkan prinsip-prinsip membina hubungan yang harmonis yaitu:

1. Mutlak adanya kejujuran dan keterusterangan. 
$\gamma$-tanzim $\begin{aligned} & \text { Hannah Mahfuzhah \& Anshari } \\ & \text { Media Publikasi Humas Dalam Pendidikan }\end{aligned}$

\section{Volume 2 Nomor 22018}

2. Memberikan pelayanan sebaik- baiknya kepada pers.

3. Menjaga prilaku ketika berhadapan dengan media.

4. Tidak menutup saluran informasi, hal ini dapat menyebabkan pers mencari pihak lain yang sifatnya tidak resmi, sehingga berita tersebut tidak dapat lagi dikontrol oleh humas.

5. Jangan membanjiri media dengan berbagai publisitas yang tidak jelas tujuannya atau sasarannya.

6. Selalu memperbarui satiap daftar indentitas reporter agar tercipta hubungan baik denga media (good media relationship). (Farihanto, 2104)

\section{MEDIA PUBLIKASI HUMAS DALAM PENDIDIKAN}

Humas atau Public Relation eksistensinya sangat diperlukan dalam suatu instansi pemerintah, badan publik bahkan dalam organisasi pendidikan. Sebagai kepanjangan tangan dari sebuah organisasi, Humas memiliki tugas mempublikasikan suatu kegiatan serta menjalin komunikasi dengan masyarakat.(Sulistyoningsih, 2017)

Di negara kita pendidikan dipandang sebagai tanggung jawab bersama antara, keluarga, masyarakat, dan pemerintah. Dan seorang manajer pendidikan harus menyadari bahwa masyarakat mempunyai peran yang sangat penting terhadap kemajuan lembaga pendidikan. Bila ada lembaga pendidikan yang mengalami kemajuan, maka salah satu penentunya karena keterlibatan yang maksimal dari masyarakat. Sebaliknya, jika ada lembaga pendidikan yang memprihatinkan, maka salah satu penyebabnya adalah masyarakat enggan memberikan dukungan.

Dalam dunia pendidikan sendiri, humas melaksanakan tugas manajerialnya diwakili oleh seorang Waka Humas. Dalam prakteknya seorang Waka Humas harus dapat menggunakan alat - alat Public Relation untuk mengubah atau mempengaruhi presepsi publik terhadap lembaga pendidikan atau mempengaruhi perilaku publik terhadap kebijakan lembaga pendidikan melalui program yang sudah direncanakan dan bersifat membujuk. Hal ini selaras dengan pernyataan William L Rivers, sebagaimana dikutip oleh Diana, yaitu "Public Relations is the skilled of communications of ideas to the various publics with the object of producing adesired result to change the public image of an individual or corporation or to order public attitude toward company police” (Diana, 2010) 
$\gamma$-tanzim $\begin{aligned} & \text { Hannah Mahfuzhah \& Anshari } \\ & \text { Media Publikasi Humas Dalam Pendidikan }\end{aligned}$

\section{Volume 2 Nomor 22018}

Kepercayaan masyarakat merupakan kunci kemajuan lembaga pendidikan. Oleh sebab itu, tugas Public Relation dalam bidang ini adalah menciptakan hubungan yang saling menguntungkan satu sama lain dengan menciptakan hubungan yang positif dengan cara-cara yang positif pula. Oleh karenannya seorang Humas perlu memahami konten dan perilaku komunikasi.(Marhaeni, 2016)

Komunikasi menjadi sangat penting karena ketidakharmonisan hubungan antara manusia dalam organisasi ataupun dalam kehidupan dimasyarakat disebabkan cara komunikasi yang keliru sehingga menimbulkan salah persepsi, miskomunikasi atau salah paham. Untuk mencegah hal tersebut, seorang Public Relation harus pandai dalam berkomunikasi dan selektif dalam memilih media publikasi.

Dengan memilih media publikasi yang baik dan sesuai, setidaknya ada 3 keuntungan yang dapat diperoleh oleh lembaga pendidikan, diantaranya: (1) Mendapatkan umpan balik (feed back) dari masyarakat atas kebijakan - kebijakan yang ditempuh lembaga, (2) Untuk menunjukkan transparansi pengelolaan lembaga pendidikan sehingga memiliki akuntabilitas publik yang tinggi, dan (3) Untuk mendapatkan dukungan riil dari masyarakat terhadap kelangsungan lembaga pendidikan.

Dewasa ini, banyak media publikasi yang dapat dimanfaatkan oleh lembaga pendidikan untuk mempublikasikan kegiatan kelembagaanya. Diantaranya adalah internet. Internet merupakan media publikasi yang dinilai lebih efektif, praktis dan efisien, karena dapat dijangkau seluruh lapisan masyarakat, di manapun dan kapanpun.

\section{PENUTUP}

Lembaga pendidikan dan masyarakat sejatinya memiliki hubungan timbal balik yang saling menguntungkan, hubungan ini harus dijaga untuk menopang masa depan masyarakat dan kelestarian lembaga pendidikan itu sendiri. Lembaga pendidikan dapat dipandang dan memberikan kesan yang baik jika keberadaanya diakui dan mendapat dukungan dari masyarakat luas.

Sama halnya dengan sebuah produk, baik produk barang maupun jasa, sejatinya jika ingin diminati konsumen dan laris di pasaran, tidak hanya harus menarik saja. Lebih dari itu, harus didukung oleh tangan - tangan kreatif dan pemikiran inovatif seorang public relation dalam melakukan promosi produk. Begitu pula dengan promosi lembaga pendidikan. 
$\gamma$-tanzim $\begin{aligned} & \text { Hannah Mahfuzhah \& Anshari } \\ & \text { Media Publikasi Humas Dalam Pendidikan }\end{aligned}$

\section{Volume 2 Nomor 22018}

Dalam mempromosikan lembaga pendidikan, public relation memegang peran yang sangat penting. Public Relation harus mempunyai strategi dalam menjalankan aktivitas manajerial, salah satunya ialah melakukan publisitas dengan mengedepankan aspek keterbukaan informasi publik, pemberitaan yang benar dan transparan. Ia juga harus cermat dalam memilih media yang akan dipakai untuk publikasi, agar pesan yang hendak disampaikan menjadi tepat sasaran. Tidak hanya itu, tugas public relation sebagai mediator antara lembaga dan publik harus selalu intens mengadakan relasi dengan media pers agar tercipta hubungan yang saling menguntungkan.

\section{DAFTAR PUSTAKA}

Abbas, F., \& Pasallo, S. (2013). Peran Media Massa Cetak (Koran) dalam Meningkatkan Pariwisata Danau Dua Rasa (Labuan Cermin), Berau. eJournal Ilmu Komunikasi, 1(4), 94.

Adhrianti, L. (2016). Digitalisasi Public Relations bagi Penguat Citra Pemerintah Daerah. In Seminar Nasional Komunikasi 2016 (p. 116).

Afkarina, N. U. R. I. (2018). Strategi komunikasi humas dalam membentuk public opinion lembaga pendidikan. Jurnal Idaarah, 2(1), 50-63.

Anom, E. (2004). Public relations dalam kegiatan marketing. Jurnal Komunikologi, 1(1), 1-5.

Aras, M. (2014). KEGIATAN GOVERNMENT PUBLIC RELATION DALAM MEMBANGUN KOMUNIKASI DENGAN DUNIA PERS : STUDI KASUS HUMAS PEMERINTAH KOTA ADMINISTRASI JAKARTA TIMUR. Humaniora, 5(2), 1056-1065.

Ardhoyo, T. E. (2013). Peran dan Strategi Humas (Public Relations) dalam Mempromosikan Produk Perusahaan. Jurnal Ilmiah WIDYA, l(1), 16.

Artis. (2011). Strategi Komunikasi Public Relation. Jurnal Sosial Budaya, 8(2), 186.

Baharun, H. (2016). Manajemen Kinerja dalam Meningkatkan Competitive Advantage pada Lembaga Pendidikan Islam. Jurnal at - Tajdid, 5(2), 244.

Diana. (2010). Strategi Pemilihan Media yang Efektif dalam Mengkomunikasikan Perusahaan pada Customer Di Panorama Tours.

DPRRI. (2008). Undang - Undang Republik Indonesia Nomor 14 Tahun 2008 tentang Keterbukaan Informasi Publik.

Dwi, E., \& Watie, S. (2011). Komunikasi dan Media Sosial ( C ommunications and Social Media ). The Messenger, 3(1), 69.

Farihanto, M. N. (2104). DAN WARTAWAN ( Studi Kasus Strategi Hubungan Media di Bidang Humas dan Protokoler Universitas Ahmad Dahlan ). Jurnal Komunikasi Profetik, 7(2), 53-64.

Griessner, C. (2012). News Agencies and Sosial Media: A Relationship with A Future.

Herlina, S. (2015). Strategi komunikasi humas dalam membentuk citra pemerintahan di kota malang. JISIP: Jurnal Ilmu Sosial Dan Ilmu POlitik, 4(3), 499.

Indrioko, E. (2015). Membangun Citra Publik dalam Lembaga Pendidikan Islam. UNIVERSUM, 9(2), 267.

Ishak, A. (2012). Peran Public Relations dalam Komunikasi Organisasi. Jurnal Komunikasi, 1(4), 373-380.

Kholisoh, N. (2015). Strategi Komunikasi Public Relations dan Citra Positif Organisasi ( Kasus Public Relations Rumah Sakit “X” di Jakarta ). Jurnal Ilmu Komunikasi, 13(3), 195-209. 
$\gamma$-tanzim $\begin{aligned} & \text { Hannah Mahfuzhah \& Anshari } \\ & \text { Media Publikasi Humas Dalam Pendidikan }\end{aligned}$

\section{Volume 2 Nomor 22018}

Marhaeni, M. \& D. (2016). Konstruksi Prinsip Kinerja Public Relations Dalam Pandangan Syariat Islam. The Messenger, 8(2), 24.

Musyarrofah, M. (2018). Peran humas dalam pengembangan pendidikan tinggi. Jurnal Idaarah, 2(1), 293-304.

Raharjo, R. S. (2016). MEDIA RELATIONS DI MEDIA MASSA ( Analisis Deskriptif Kualitatif Terhadap Kegiatan Media Relations TVRI Yogyakarta dan Jogja TV ). Profetik Jurnal Komunikasi, 9(2), 1-14.

Rahmat, A. (2016). Manajemen Humas Sekolah (1st ed.). Yogyakarta: Media Akademi.

Rahutomo, A. N. (2013). Strategi Humas Pelayanan Publik PT PLN di Samarinda. eJournal Ilmu Komunikasi, 1(2), 324-340.

Sulistyoningsih. (2017). Strategi humas dan protokol terhadap publikasi kegiatan DPRD DIY. Profetik Jurnal Komunikasi, 10(1), 128.

Surbakti, D. (2015). Peran dan Fungsi Pers Menurut Undang - Undang Pers Tahun 1999 Serta Perkembangannya. Jurnal Hukum Prioris, 5(1), 78.

Toding, B. (2017). PADA BIRO HUMAS DAN PROTOKOL PEMERINTAH, 5(1), 209.

Wahyuni, N. Y. (2018). PENCITRAAN: UPAYA MEMBANGUN PUBLIC OPINION BAGI LEMBAGA PENDIDIKAN ISLAM. Al-Tanzim, 2(1), 64-79. 